\title{
UBER: TRABALHO PRECARIZADO EM TEMPOS DE ECONOMIA DE COMPARTILHAMENTO NA CIDADE DE BELÉM
}

Francisco Leandro Martins Lameira

Graduado em Ciências Sociais na Universidade Federal do Pará, UFPA, Brasil. E-mail: leandromartins2510@gmail.com

Tânia Guimarães Ribeiro

Professora da Faculdade de Ciências Sociais e do Programa de Pós-Graduação em Sociologia e Antropologia do IFCH-UFPA. Email: ptolomeu@gmail.com

\section{RESUMO}

Esse estudo tem o objetivo de analisar, por meio de uma perspectiva sociológica, o processo de precarização do trabalho dos motoristas que estão registrados na plataforma tecnológica da empresa Uber, na região metropolitana de Belém, Estado do Pará. Desse modo, é necessário estudar as condições de trabalho dos motoristas, caracterizar o fenômeno da Uberização sob o olhar da sociologia do trabalho e descrever a percepção dos motoristas sobre as suas atividades laborais. A Uber é considerada uma startup, isto é, uma atividade privada de prestação de serviços com utilidade pública baseada na interconexão tecnológica de utilizadores através da internet. Fornece uma plataforma tecnológica para smartphones que tem como função estabelecer a conexão entre passageiros, que desejam se transportar; e motoristas, que desejam realizar o serviço mediante renumeração. Para isso, é necessário que ambos estejam previamente cadastrados no aplicativo da consulente para que o contato seja possível. Essa pesquisa utiliza a metodologia qualitativa com base em entrevistas com os motoristas cadastrado na empresa Uber, bem como foi utilizado a pesquisa bibliográfica de caráter exploratório a partir da leitura de livros, artigos, Trabalhos de Conclusão de Curso, dissertações e pesquisas relacionadas ao tema. Esse estudo constatou que o trabalho dos motoristas da Uber se enquadra no tipo de trabalho precário caracterizado pela literatura sociológica do trabalho (ANTUNES, 2002), cujo sistema capitalista se apropria para sua manutenção enquanto modo de produção. E o conceito de uberização (Slee, 2017) refere-se ao avanço da economia do compartilhamento, ancorada nas plataformas digitais que nos leva ao seguinte questionamento: Qual a relação entre o avanço tecnológico e a precarização do trabalho na sociedade informacional? Tendo em vista o exposto, a Uber é um exemplo de dispositivo digital que deteriora as relações trabalhistas e transforma o que seria liberdade dos trabalhadores em escravidão moderna. 
PALAVRAS-CHAVE: Uber. Belém. Precarização do Trabalho.

\title{
UBER: PRECARIOUS WORK IN TIMES OF SHARING ECONOMY IN THE CITY OF BELÉM
}

\begin{abstract}
This study aims to analyze, through a sociological perspective, the process of precarious work for drivers registered on the technological platform of the Uber company, in the metropolitan region of Belém, State of Pará. Thus, it is necessary to study the drivers 'working conditions, characterizing the phenomenon of Uberization from the perspective of sociology of work and describing the drivers' perception of their work activities. Uber is considered a startup, that is, a private activity of providing services with public utility based on the technological interconnection of users through the internet. Provides a technological platform for smartphones whose function is to establish the connection between passengers, who wish to transport themselves; and drivers, who wish to perform the service by means of remuneration. For this, it is necessary that both are previously registered in the application of the querent so that the contact is possible. This research uses the qualitative methodology based on interviews with drivers registered with the Uber company, as well as an exploratory bibliographic research based on reading books, articles, Course Conclusion Papers, dissertations and research related to the theme. This study found that the work of Uber drivers fits into the type of precarious work characterized by the sociological literature of work (ANTUNES, 2002), whose capitalist system is appropriate for its maintenance as a mode of production. And the concept of uberization (Slee, 2017) refers to the advancement of the sharing economy, anchored on digital platforms that leads us to the following question: What is the relationship between technological advancement and the precariousness of work in the information society? In view of the above, Uber is an example of a digital device that deteriorates labor relations and transforms what would be workers' freedom into modern slavery.
\end{abstract}

KEYWORDS: Uber. Belém. Precarious Work.

\section{INTRODUÇÃO}

Foi em um período de crise profunda no Brasil que formas de trabalho por meio de aplicativos, igualmente a Uber, se tornaram o símbolo de empregos informais, temporários e mau-renumerados, mas também uma forma de obter renda. Milhares de pessoas sem perspectivas de encontrar um emprego fixo preferem trilhar o caminho de um contingente cada vez maior no Brasil: utilizar aplicativos para smartphones como forma de trabalho. 
O mundo do trabalho já não é mais o mesmo. As transformações são cada vez mais intensas em virtude do grande salto tecnológico, com a introdução da robótica, automação e da microeletrônica nos diferentes meios de produção. E na atual era da sociedade informacional, surgem relações de trabalho intermediadas por aplicativos como forma de geração de emprego precária no Brasil.

Diante de várias empresas virtuais, que utilizam tecnologia de informação em seus modelos de negócios, a Uber é umas das mais conhecidas atualmente no mercado. Seu impacto foi tão grande no mundo dos negócios que foi criado o conceito "Uberização" do trabalho (Slee, 2017) para expressar a ideia de precarização do trabalho na era de grande salto tecnológico que a sociedade passou e continua a passar. Para muitos pensadores do ambiente acadêmico, a palavra Uber tornou-se sinônimo de precarização em uma nova fase de relações capitalistas do trabalho.

Diante de vários questionamentos realizados sobre o trabalho dos motoristas da Uber, esse ensaio discute a seguinte questão: Há precarização no trabalho dos motoristas registrados na plataforma tecnológica da empresa Uber na cidade de Belém? Sabendo que esse estudo tem relevância para a compreensão de realidade social brasileira, foi necessário situá-lo no tempo, no espaço, circunscrevendo seus limites.

\section{DESENVOLVIMENTO}

O estudo sobre o trabalho dos motoristas da Uber se desenvolveu ao longo de 2018, tendo como base as entrevistas com os motoristas da empresa, na cidade de Belém. Eles são de um contingente de mais de 3 milhões de motoristas registrados na plataforma tecnológica da empresa, no mundo inteiro, conforme conta no site da própria empresa. Desses, 500 mil deles são brasileiros ${ }^{1}$. Todavia, não foi possível obter a informação exata do número de motoristas que estão executando essa forma de trabalho atualmente na grande Belém². Contudo, de acordo com as fontes de jornais da cidade, foi possível fazer a estimativa de que na capital paraense existem mais de 10 mil motoristas de aplicativos que utilizam a plataforma tecnológica da

\footnotetext{
${ }^{1}$ Essa informação foi retirada do próprio site da empresa Uber no seguinte endereço eletrônico: https://www.uber.com/pt-BR/newsroom/fatos-e-dados-sobre-uber/ Data: em setembro de 2018

${ }_{2} \mathrm{O}$ dado não consta no site oficial da empresa. E em contato com a empresa em Belém, não disponibilizaram números oficiais, bem como a SETRANSBEL (Secretaria de Transporte de Belém de Belém) não souber informar.
} 
Uber e outros similares a esse modelo de negócio, tais como: 99Pop, Moobi, 4move, entre outras $^{3}$. Contingente considerável de motoristas circulando na grande Belém, impactando o trânsito e o meio ambiente.

O suporte metodológico que orientou o processo de investigação desse estudo foi a utilização da pesquisa qualitativa, que é "aquela que não se preocupa com a representatividade numérica, mas sim, com o aprofundamento da compreensão de um grupo social", segundo Gerhard e Silveira (2009 apud KRAMER, 2017, p. 16). Sendo assim, foram realizadas 14 motoristas, entre os quais 6 deles moram nas cidades satélites de Belém (Marituba e Ananindeua), mas que executam seus trabalhos na capital paraense. E os demais são da própria capital. Além disso, foram consultados jornais locais e nacionais, bem como sites de notícias e de pesquisa que colaboraram para conhecer um tema que ainda requer aprofundamentos sobre o contexto da cidade de Belém, conforme dada a existência de poucos trabalhos científicos sobre a questão na região.

A pesquisa teve como objetivo geral analisar, por meio de uma perspectiva sociológica, o processo de precarização do trabalho dos motoristas que estão registrados na plataforma tecnológica da empresa Uber, na cidade de Belém-Pa. E nesse processo foi importante entender as mudanças locais conectadas a um contexto de mudanças mais amplo, tais como: as atividades da empresa Uber são parte das mudanças tecnológicas globais e com repercussões na sociabilidade; configuram as metamorfoses no mundo do trabalho apontando para os problemas da flexibilização, terceirização e desregulamentação das atividades laborais; o que resulta na seguinte questão: como os motoristas da Uber em Belém percebem estas mudanças no seu cotidiano?

Com relação as mudanças tecnológicas globais e suas repercussões na sociabilidade, a Uber está inseria em um novo modelo de negócio chamado de Economia de Compartilhamento, que propaga o discurso do microempreendedorismo. Tais elementos constituem os valores e o discurso da empresa, assim como também foi discutida a operacionalização do tipo de serviço

${ }^{3}$ Essa informação foi retirada do jornal online $\mathrm{O}$ Liberal no seguinte endereço eletrônico: <https://www.oliberal.com/belem/motoristas-de-aplicativos-querem-audi\%C3\%AAncia-com-zenaldo-ap\%C3\%B3s-protestos1.65930> Acessada em: 05 de março de 2019 
(funcionamento) tanto com relação aos motoristas quanto com relação aos usuários.

Paralelamente, buscamos compreender as transformações do mundo do trabalho questionando se seremos futuramente trabalhadores mais flexibilizados, terceirizados e desregulamentados. A partir da literatura, (CASTELS, 1999) abordamos que, ao longo dos anos, a organização do trabalho conhecida como fordismo/taylorismo foi sendo substituída ou mesclada pelo toyotismo e a presença maciça das tecnologias da informação no mundo do trabalho foi delineando o que a literatura (ANTUNES, 1999) chama de acumulação flexível do capital. Esses elementos sinalizam tendências atuais que configuram um quadro crítico que estamos vivendo atualmente no mundo do trabalho.

Nessa perspectiva, analisamos que a Uber, indubitavelmente, se enquadra no tipo de trabalho precário discutida em “Adeus ao trabalho?” (ANTUNES, 2002), cujo sistema capitalista se apropria para a sua manutenção enquanto modo de produção. A precarização no trabalho dos motoristas da Uber está forte ligada ao desenvolvimento tecnológico (Uberização) e isso foi constatado a partir dos seguintes elementos presentes no trabalho deles: a flexibilidade (trabalham mais de 10 horas por dia, nos finais de semana, pela madrugada para conseguir uma renda satisfatória no final do mês e a carteira de trabalho não assinada implica na não garantia de direitos trabalhistas); a autonomia (não são trabalhadores independentes na medida que tem cumprir várias regras impostas pela Uber, que se não forem cumpridas, podem ser expulsos da plataforma tecnológica), a presença do princípio just in time (a produção no trabalho é de acordo com a demanda do mercado), um nova de gerenciamento (executado pelo consumidor através do sistema de avaliação que é entendido como uma forma de controle no trabalho) e individualização no trabalho (em virtude de a Uber considerar os motoristas como trabalhadores terceiros independentes, observamos a perda de solidariedade no trabalho como categoria de trabalhadores o que implica na dificuldade de se formar associações ou sindicatos).

\section{CONSIDERAÇÕES FINAIS}

Nos três desenhos expostos, podemos observar as crianças sendo representadas em diversos contextos de trabalho e vulnerabilidade. Na figura 1, observa-se um garoto trabalhando como empacotador em um supermercado. $\mathrm{O}$ autor do desenho, demonstra um adolescente, trabalhando na condição de aprendiz como empacotador. Neste contexto, inferese que o garoto retratado está protegido pelas legislações que o resguardam na estrutura do 
ensino aprendizagem, com provável acesso à escola conforme o ECA preconiza.

Por fim, analisamos que a Uber é, sem dúvida, um exemplo de economia de plataforma e de serviços com uso de dispositivo digital que precariza as relações trabalhistas. A empresa transforma o que seria liberdade dos trabalhadores em um tipo de escravidão moderna. Vivemos em tempos em que a organização e a estruturação do trabalho já não são as mesmas das experiências capitalistas anteriores, pois novos processos e organizações do trabalho surgiram na era da sociedade informacional, marcada pelo advento das tecnologias da informação que vem remodelando a sociedade de forma intensa e profunda.

Vivemos atualmente uma onda de desregulamentação que se acentua no atual contexto político brasileiro, no qual empreendimentos privados e direitos sociais amplificaram o seu antagonismo pela falta de qualquer regulamentação estatal. A informalidade está cada vez mais presente, onde o contingente de trabalhadores precários, informais e vulneráveis só tende a crescer. E as novas tecnologias informacionais, que sustentam as atividades através das plataformas digitais, contribuem para a intensificação deste cenário crítico. Com o ataque maciço ao trabalho formal com direitos trabalhistas fixos, a precarização, via o progresso da tecnologia, mais uma vez "não entrega o que promete": a emancipação social. Pelo menos, não para os pequenos.

\section{REFERÊNCIAS BIBLIOGRÁFICAS}

ANTUNES, Ricardo. Adeus ao trabalho? Ensaio sobre as metamorfoses e a centralidade do mundo do trabalho. 8. ed. São Paulo: Cortez Editora, 2002.

CASTELLS, Manuel. A sociedade em rede, Paz e Terra, São Paulo, 1999.
CASTELLS, Manuel. A sociedade em rede: a era da informação, economia, sociedade e cultura. São Paulo: Paz e Terra, 1999.

SLEE, Tom. Uberização: a nova onda do trabalho precarizado. São Paulo: Editora Elefante, 2017. p. 320

LAMEIRA, F. L. M., RIBEIRO, T. G. Uber: Trabalho Precarizado em Tempos de Economia de Compartilhamento na Cidade de Belém. Complexitas - Rev. Fil. Tem. Belém, v. 4, n. 1, p. 79-84, jan./jun. $2019 . \quad$ Disponível em: http://www.periodicos.ufpa.br/index.php/complexitas/article/view/8047>. Acesso em: 30 de janeiro de 2020. 